\title{
Article \\ Synthesis and Characterisation of Alginate-Based Capsules Containing Waste Cooking Oil for Asphalt Self-Healing ${ }^{\dagger}$
}

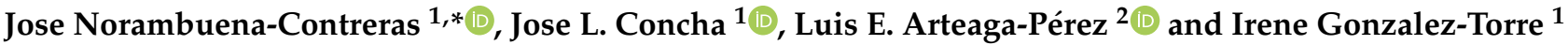 \\ 1 LabMAT, Department of Civil and Environmental Engineering, University of Bío-Bío, \\ Concepción 4051381, Chile; jlconcha@ubiobio.cl (J.L.C.); irenegon@ubiobio.cl (I.G.-T.) \\ 2 LPTC, Department of Wood Engineering, University of Bío-Bío, Concepción 4051381, Chile; \\ larteaga@ubiobio.cl \\ * Correspondence: jnorambuena@ubiobio.cl \\ + This paper is an extended version of the awarded best paper published in the Resilient Materials 4 Life \\ International Conference (RM4L2020), Cambridge, UK, 20-23 September 2021.
}

Citation: Norambuena-Contreras, J.; Concha, J.L.; Arteaga-Pérez, L.E.; Gonzalez-Torre, I. Synthesis and Characterisation of Alginate-Based Capsules Containing Waste Cooking Oil for Asphalt Self-Healing. Appl. Sci. 2022, 12, 2739. https://doi.org/ 10.3390/app12052739

Academic Editor: Roberto Zivieri

Received: 12 January 2022

Accepted: 3 March 2022

Published: 7 March 2022

Publisher's Note: MDPI stays neutral with regard to jurisdictional claims in published maps and institutional affiliations.

Copyright: (C) 2022 by the authors. Licensee MDPI, Basel, Switzerland. This article is an open access article distributed under the terms and conditions of the Creative Commons Attribution (CC BY) license (https:// creativecommons.org/licenses/by/ $4.0 /)$.
Featured Application: This work is a preliminary study for the potential application of biopolymeric polynuclear capsules containing waste cooking oil as a promising encapsulated rejuvenator for microcrack self-healing in long-term aged bitumen.

\begin{abstract}
This paper presents the synthesis and characterisation of biopolymeric capsules for asphalt self-healing. A sodium alginate biopolymer extracted from the cell wall of brown algae was used as the encapsulating material to contain Waste Cooking Oil (WCO) as a potential encapsulated rejuvenating agent for aged bitumen. Polynuclear capsules were synthesised by ionic gelation. The size, surface aspect and internal structure of the WCO capsules were evaluated using Optical and Scanning Electron Microscopy. The physical-chemical properties and thermal stability of the WCO capsules and their components were also evaluated. Moreover, the diffusion process and self-healing capability of the released WCO on cracked bitumen test samples were determined by image analysis through fluorescence microscopy. The main results of this study showed that the WCO capsules presented a suitable morphology to be mixed in asphalt mixtures. WCO capsules and their components presented mechanical and thermal stability and physical-chemical properties which suggest their feasibility for self-healing applications. It was proven that the encapsulated WCO can diffuse in the aged bitumen, reducing its viscosity and promoting the self-healing of microcracks.
\end{abstract}

Keywords: waste cooking oil; polynuclear capsule; asphalt rejuvenator; ageing; self-healing

\section{Introduction}

Self-healing by the action of encapsulated rejuvenating agents has been considered as a revolutionary technology for autonomous crack-healing of asphalt materials [1]. Asphalt materials are complex viscoelastic composites mainly used for asphalt pavement construction. Cracking of asphalt materials mainly occurs due to the oxidation of the hydrocarbons in the bitumen by the action of operation and environmental agents [2]. When damage occurs in an asphalt material containing embedded encapsulated rejuvenators, cracks appear and eventually propagate until they reach and break or deform a capsule, releasing the contained rejuvenating agent. Rejuvenating agents consist of lubricating and extender oils with high proportions of maltene constituents, which restore the asphaltenes/maltenes ratio in the aged bitumen during healing [3]. When the rejuvenating agent is released from inside the capsule (i.e., activation of polynuclear or core-shell capsules by deformation or break), the molecules of the released rejuvenator diffuse into the asphalt matrix and soften the aged bitumen, allowing the rejuvenated bitumen to flow through the open microcracks, thus facilitating the crack self-healing process [4]. Figure 1 shows the concept of self-healing asphalt by the action of encapsulated rejuvenators. 


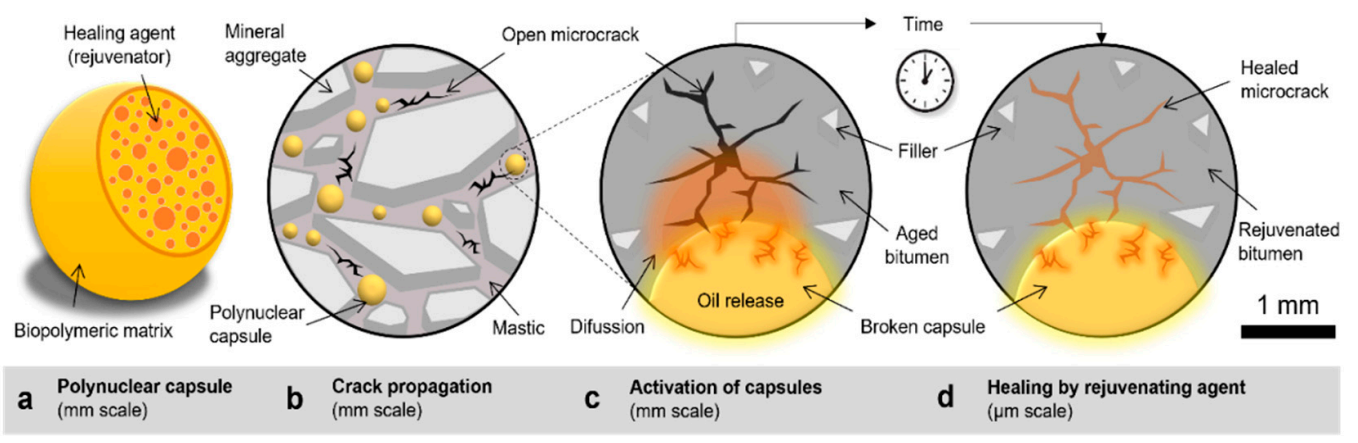

Figure 1. Concept of self-healing in asphalt using encapsulated rejuvenators. (a) Polynuclear capsules are spherical particles with the encapsulated material distributed throughout a polymeric porous matrix structure. (b) Propagation of microcracks in an asphalt mixture incorporating polynuclear capsules. (c) Microcracks reach a polynuclear capsule resulting in their superficial rupture, and so, releasing the encapsulated healing agent (i.e., WCO). (d) The healing agent diffuses into the cracked zone with a softening effect on the aged bitumen, sealing the damaged area.

Recent studies have successfully proven the efficacy of numerous oils as promising, more sustainable alternatives for the design of encapsulated rejuvenators for aged asphalt, such as dense aromatic oil [5], waste cooking oil [6], mineral engine oil [7], sunflower oil [8] and, recently, bio-oil from liquefied agricultural biomass waste [9] and pyrolytic oil from waste tyres pyrolysis [10]. However, the polymers currently used for the encapsulation process, for example melamine-formaldehyde [6], can give rise to a potentially high environmental risk from the leaching of hazardous chemical compounds. Therefore, more sustainable capsules based on biopolymers are necessary to make this technology suitable for use in a new generation of asphalt pavements [11].

Sodium alginate is a biopolymer water-soluble polysaccharide extracted from the cell wall of various species of brown algae. Aspects such as great availability, low cost [12], high capacity to form a gel at low concentrations, nontoxicity, biocompatibility [13], and long-term stability [14] make sodium alginate a promising encapsulating material, reducing the negative environmental impact of typical polymers. Currently, the use of alginate as an encapsulating material of rejuvenators for asphalt has been explored by many authors. Experimental work was carried out by Norambuena-Contreras et al. in stone mastic asphalt [15] and a dense mixture [16]; the authors concluded that the addition of alginatebased capsules with sunflower oil and incorporated in a concentration of $0.5 \%$ per total weight of mixture significantly improved the healing capability of the respective mixtures. More currently, Ruiz-Riancho et al. [17] characterised alginate-biopolymer polynuclear capsules with virgin sunflower oil as a rejuvenator, proving that the strength of the capsules was influenced by the pore size of the calcium-alginate structure, and that the capsules could resist the temperature that is reached during asphalt mixing and compaction.

Despite the urgent need to develop more sustainable and resilient construction materials, and the extensive diversity of renewable resource-based polymers for these purposes, the use of biomaterials in the civil engineering industry remains limited. Studies on the control and design variables for the correct synthesis of alginate-based capsules for asphalt self-healing purposes are still very limited in number. This study aims to synthesise and characterise polynuclear biopolymeric capsules for asphalt self-healing, where a sodium alginate biopolymer from the cell wall of brown algae Laminaria hyperborea was used as the encapsulating material. Waste Cooking Oil was encapsulated in biopolymer as a potential rejuvenating agent to design more sustainable asphalt roads, because its content of light oil components is similar to that of bitumen. As an innovative approach, aspects such as (1) the adequate hydration of the biopolymer before encapsulation, (2) the control of the physical stability of the oil-in-water $(\mathrm{O} / \mathrm{W})$ emulsion, and (3) adequate height between the outgoing emulsion from the needle tip and the hardening solution are reported in this study. 


\section{Materials and Methods}

\subsection{Materials}

Biopolymeric capsules containing Waste Cooking Oil for asphalt self-healing were prepared in this study. The polymeric structure of the capsules was prepared from lowviscosity grade sodium alginate (viscosity @20 ${ }^{\circ} \mathrm{C} 200-300 \mathrm{cP}$ for $2 \% w / v$ solution) provided by Buchi (Flawil, Switzerland), and calcium-chloride dihydrate $\left(\mathrm{CaCl}_{2} \cdot 2 \mathrm{H}_{2} \mathrm{O}\right)$ with $70 \%$ purity provided by Winkler (Concepción, Chile). Waste Cooking Oil coming from recycled sunflower oil after one-cycle frying at $180{ }^{\circ} \mathrm{C}$ (density $0.85 \mathrm{~g} / \mathrm{cm}^{3}$, viscosity @20 ${ }^{\circ} \mathrm{C} 89 \mathrm{cP}$ and $\left.\mathrm{pH} @ 25^{\circ} \mathrm{C} 4.4-4.6\right)$ was used as a sustainable rejuvenating agent. Additionally, a virgin bitumen with density $1.04 \mathrm{~g} / \mathrm{cm}^{3}$ and penetration grade $50 / 70$ (penetration $60 \times 10^{-1} \mathrm{~mm}$ @25 ${ }^{\circ} \mathrm{C}$ and softening point $50{ }^{\circ} \mathrm{C}$ ) was long-term aged by standard Pressure Air Vessel (PAV) tests [18] to quantify the self-healing efficiency of the Waste Cooking Oil in aged asphalt. The PAV test was carried out at $100^{\circ} \mathrm{C}$ for $20 \mathrm{~h}$, simulating the bitumen's long-term ageing during its service life [11].

\subsection{Synthesis of WCO Capsules by Dripping Method}

WCO capsules were synthesised in the laboratory through the cross-linking of sodium alginate in the presence of calcium ions $\left(\mathrm{Ca}^{2+}\right)$ by ionic gelation, using the microfluidic pressure pump method. This method is based on the procedure described by NorambuenaContreras et al. [9]. Briefly, an aqueous solution of sodium-alginate with a concentration of $2 \%$ of weight by volume of water was used to produce capsules. The alginate solution was maintained in constant agitation for $24 \mathrm{~h}$ using a magnetic stirrer (Scilogex, Model SCI550-S, Rocky Hill, CO, USA) to properly hydrate the biopolymer, based on the recommendation of Norambuena-Contreras et al. [10]. The solution was then mixed with WCO to generate a WCO-in-alginate emulsion, which is then pumped $(2 \mathrm{~mL} / \mathrm{min})$ via an automatic microfluidic device (New Era NE-1010, Farmingdale, NY, USA) through a hollow metal needle (ID: $1.2 \mathrm{~mm})$ into a calcium-chloride $\left(\mathrm{CaCl}_{2}\right)$ solution acting as a hardener, which was in constant agitation using a magnetic stirrer at $250 \mathrm{rpm}$. The height of separation between the needle tip and the hardening solution was settled to $350 \mathrm{~mm}$ since a higher height could result in the break of the droplets when dropped in the solution, as reported by Martins et al. [13]. A graphical representation of this encapsulation procedure is shown in Figure 2. Finally, produced WCO capsules (approximately $50 \mathrm{~g}$ in total) were placed into a container and stored in a freezer at $-18{ }^{\circ} \mathrm{C}$ to avoid the oxidation of the encapsulated rejuvenating agent.

\subsection{Experimental Characterisation of the WCO Capsules and Their Components}

The size, surface aspect and internal microstructure of the WCO capsules synthetised according to Figure 2 were characterised by Optical (Leica EZ4, Wetzlar, Germany) and Scanning Electron Microscopy (Hitachi SU 3500, Chiyoda, Tokyo, Japan), respectively. Additionally, the presence of chemical elements in the surface of polynuclear WCO capsules was evaluated by Scanning Electron Microscope (SEM) coupled to energy dispersive Xray spectroscopy (EDS, Bruker Quantax 100, Billerica, MA, USA) for semi-quantitative determinations. Encapsulation efficiency of the WCO capsules was also quantified by a chemical procedure based on Guadarrama-Lezama et al. [19]. Bulk density and uniaxial compressive strength (@20 ${ }^{\circ} \mathrm{C}$ and loading rate $0.2 \mathrm{~mm} / \mathrm{min}$ using a Universal Testing Machine, Test Resources, Shakopee, MN, USA) of the capsules were measured by the test method B of ASTM D792-13 [20] and ASTM D695-02a [21], respectively. 


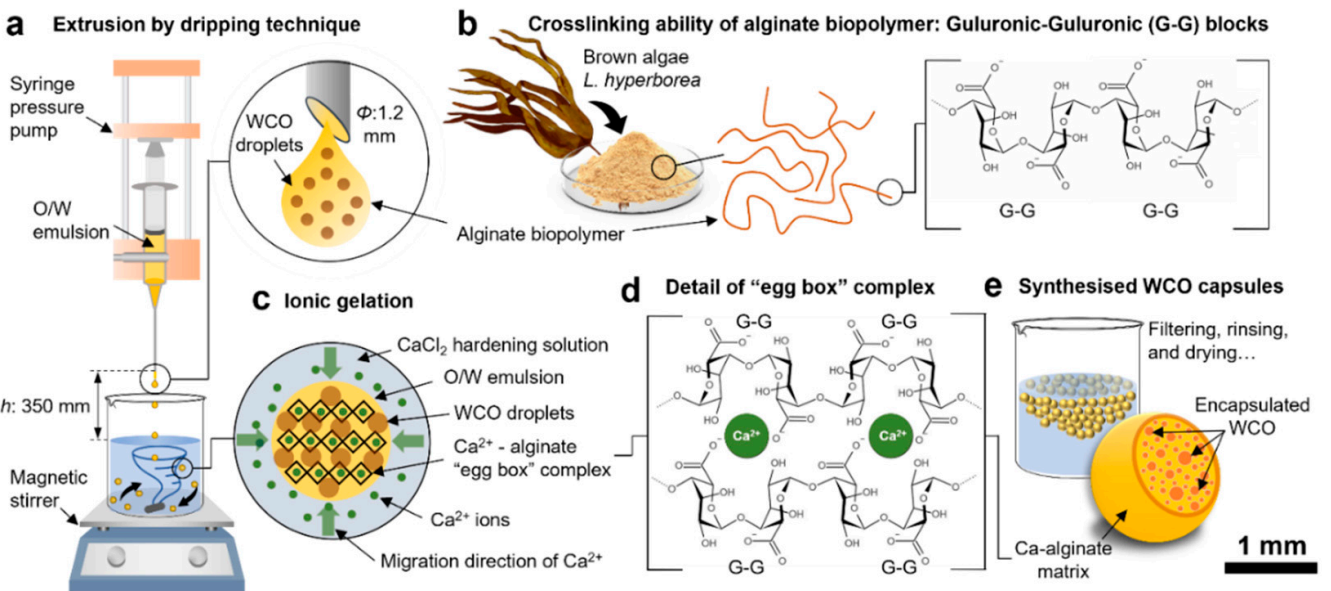

Figure 2. Representation of the procedure to synthetise polynuclear capsules containing WCO as rejuvenator. (a) First, an alginate-based $\mathrm{O} / \mathrm{W}$ emulsion containing $\mathrm{WCO}$ is extruded by using a syringe pressure pump. (b) The alginate biopolymer present in the emulsion possesses GuluronicGuluronic (G-G) molecular blocks structures with the capacity to crosslink in the presence of divalent $\mathrm{Ca}^{2+}$ ions. Thus, when the extruded $\mathrm{O} / \mathrm{W}$ emulsion drop into a $\mathrm{CaCl}_{2}$ bath (c) the ionic gelation process take place by exchanging the $\mathrm{Na}^{+}$ions from carboxylic acids in the G-G blocks with $\mathrm{Ca}^{2+}$ ions, resulting in (d) the well-known "egg-box" crosslinked complex. In the end, (e) capsules are formed, where the Ca-alginate complex encapsulate the WCO in multiple cavities. Figure inspired on Norambuena-Contreras et al. [9].

The individual constituents used for synthesising the WCO polynuclear capsules (see Figure 2) were also characterised. The physical stability of the $\mathrm{O} / \mathrm{W}$ emulsion was evaluated through the creaming index, by measuring the separation of the WCO oil droplets from the alginate solution as proposed by McClements [22], and recently used by Concha et al. [23]. Fourier transform infrared spectrometer in mode of attenuated total reflection (FTIR-ATR) of the WCO and its comparison with a Virgin Cooking Oil (VCO) was recorded in a Perkin Elmer Spectrum Two spectrometer (Waltham, MA, USA) between 400 and $4000 \mathrm{~cm}^{-1}\left(20\right.$ Scans at $\left.2 \mathrm{~cm}^{-1}\right)$. Additionally, thermogravimetric analysis and derivative thermogravimetry (TGA-DTG) of WCO was carried out between ambient and $600{ }^{\circ} \mathrm{C}$ at $10^{\circ} \mathrm{C} / \mathrm{min}$ in $\mathrm{N}_{2}(10 \mathrm{~mL} / \mathrm{min}$ ) in a TA Tech Q50 thermobalance (New Castle, DE, USA).

Finally, the healing capacity of WCO to seal a microcrack overtime on long-term ageing bitumen samples by Pressure Air Vessel (PAV-samples) was evaluated under the current method proposed by Norambuena-Contreras et al. [9,10]. For that, a $\sim 2 \mathrm{mg}$ drop of WCO was dropped on a cracked-PAV bitumen sample with dimensions $20 \times 20 \times 0.5 \mathrm{~mm}$ and an artificial microcrack of $200 \mu \mathrm{m}$-width along the sample. The $\mu$-crack closure over time by the effect of WCO diffusion was recorded by images using an inverted fluorescence microscope (ICOE IV 5100 FL, Ningbo, China). Crack-width was measured at six positions using the image software Image ${ }^{\circledR}$ (Fiji distribution, version 1.52p, National Institutes of Health, Bethesda, MD, USA). The complete crack closing process was recorded in a maximum time of $85 \mathrm{~min}$ [9]. Lastly, the healing efficiency of the WCO over time was quantified as the relationship between the average crack-width at a specific time measured in $\mu \mathrm{m}$ and the average initial crack-width measured in $\mu \mathrm{m}$ [10].

\section{Results and Discussion}

\subsection{Physical-Mechanical Properties of the Synthesised Capsules}

Figure 3 presents the main results of experimental characterisation of the WCO capsules. Statistical size analysis of 100 individual WCO capsules registered an average size of $1.649 \mathrm{~mm}(\mathrm{SD}=0.145 \mathrm{~mm}$ ), with a spherical and uniform geometry (Figure 3a). These capsules presented an encapsulation efficiency of WCO close to $90 \%$. SEM-EDS observations (Figure $3 \mathrm{~d}$ ) proved that WCO capsules reveal a polynuclear structure on their 
surface (Figure $3 \mathrm{~b}, \mathrm{c}$ ) with an elemental composition of $\mathrm{Ca}(73 \%)$ and $\mathrm{Na}(27 \%)$, which is consistent with the materials used for the synthesis of the porous Ca-alginate matrix structure in the presence of divalent calcium cations $\left(\mathrm{Ca}^{2+}\right)$ allowing that the oil-in-alginate can be cross-linked.
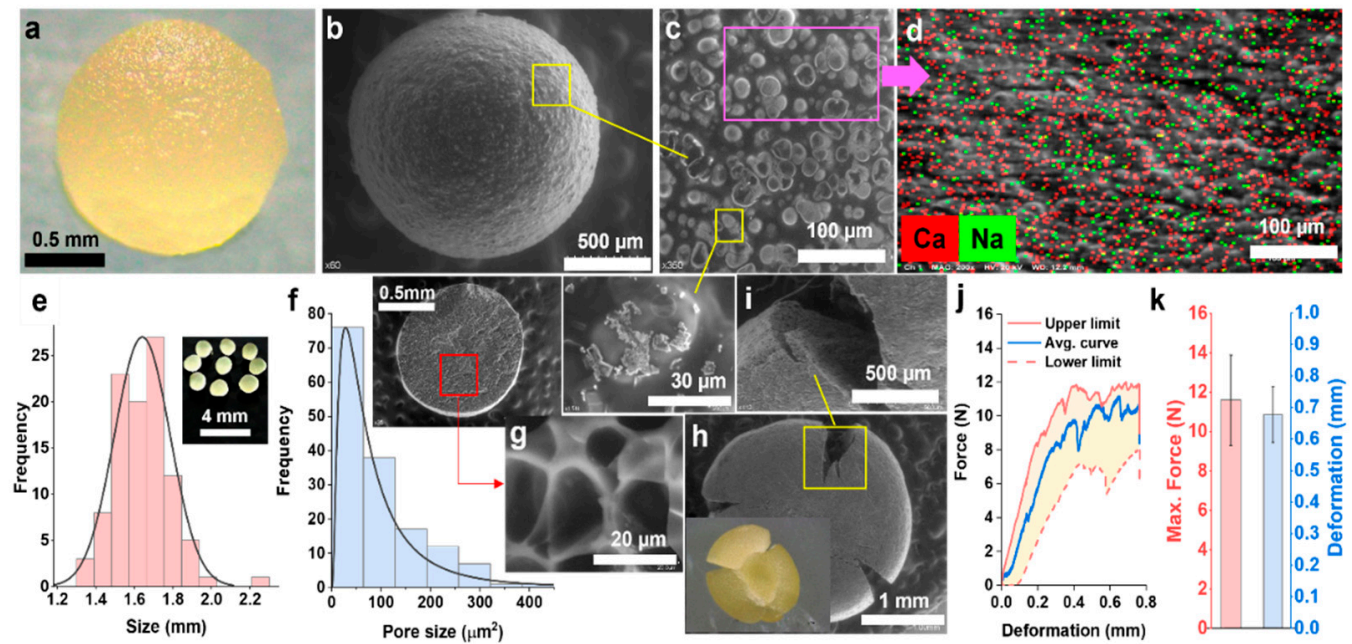

Figure 3. Experimental characterisation of WCO capsules: (a) Optical image of capsule; (b) SEM image of capsule; (c) SEM detail image of polynuclear surface structure of capsule; (d) SEM-EDS observation on the capsule surface; (e) Frequency histogram of the size of capsules with Normal fitting; (f) Frequency histogram of the pore size of internal structure of capsules with Log-normal fitting; (g) SEM image of the multicavity (egg-box) structure into capsules; (h) SEM image of an individual broken capsule by uniaxial compression; (i) Detail by SEM image of the fracture type in the broken capsule; ( $\mathbf{j}$ ) Force and deformation average curves of the compression tests; and (k) Average values of the max. compression force and deformation registered by the capsules tested by a load cell of $1 \mathrm{kN}$ at a speed rate of $0.2 \mathrm{~mm} / \mathrm{min}$.

The size distribution of WCO capsules is shown by the frequency histogram in Figure 3e, proving that the capsule size can be fitted to the normal probability distribution ( $p$-value 0.405 given by A-D test). Conversely, Figure $3 f$ shows the pore size distribution of the internal multicavity of the WCO capsules. The frequency histogram proves that the capsule pore size can be fitted to the log-normal probability distribution function ( $p$-value 0.159 given by A-D test). This Figure revealed that the internal structure of the capsules was characterised by micropores with areas $<120 \mu^{2}$ and with an occurrence probability of $75 \%$. Thus, the WCO was majorly encapsulated into small internal pores, contributing to homogeneously distribute the oil into the overall volume of the capsule.

Additionally, Figure 3h,i show SEM images of an individual capsule and the fracture type on a capsule broken by effect of a compression test, respectively. This result proves that WCO capsules can break and partially release the encapsulated WCO by effect of an external trigger. Biopolymeric matrix presented an elastic-plastic mechanical behaviour with breakage in plastic deformation around the propagating cracks, see Figure 3i,j. WCO capsules registered an average maximum compressive force of $11.6 \mathrm{~N}(\mathrm{SD}=2.3 \mathrm{~N})$ at an average maximum deformation of $0.7 \mathrm{~mm}(\mathrm{SD}=0.1 \mathrm{~mm})$, Figure $3 \mathrm{k}$. This result suggests that polynuclear WCO capsules can resist the asphalt manufacturing process (i.e., mixing and compaction) based on the results published by Garcia et al. [4] and NorambuenaContreras et al. [8] (minimum compressive force of $10 \mathrm{~N}$ ); hence, WCO capsules can be used as a resistant encapsulated rejuvenator for asphalt mixture self-healing.

\subsection{Physical Stability of Components of the Capsules}

Furthermore, the characterisation of the capsule's components was also evaluated. Physical separation of the O/W components (i.e., WCO and alginate biopolymer solution) 
is described by the creaming process in Figure $4 \mathrm{a}$. Figure $4 \mathrm{~b}$ shows that the average creaming index results increased with time, and after $30 \mathrm{~h}$ the creaming index was $83.02 \%$ corresponding to the total separation of the $\mathrm{O} / \mathrm{W}$ emulsion. This phenomenon was mainly attributed to the increase in size of the WCO droplets with time by means of coalescence, favouring the ascension of the oil droplets to form a creamed layer. Evidence of this aggregation phenomenon between the oil droplets is shown by the microscopic fluorescence images in Figure $4 \mathrm{c}-\mathrm{e}$, and further quantified by the droplet size frequency histograms in Figure $4 \mathrm{f}-\mathrm{h}$. For the successful synthesis of the WCO capsules, physically stable O/W emulsion must be used during the encapsulation process, and so, the creaming effect should be controlled. Thus, based on this analysis, the encapsulation of the $\mathrm{O} / \mathrm{W}$ emulsion should take place for a time no longer that $2 \mathrm{~h}$ since the emulsion is fabricated and kept in response at ambient temperature.

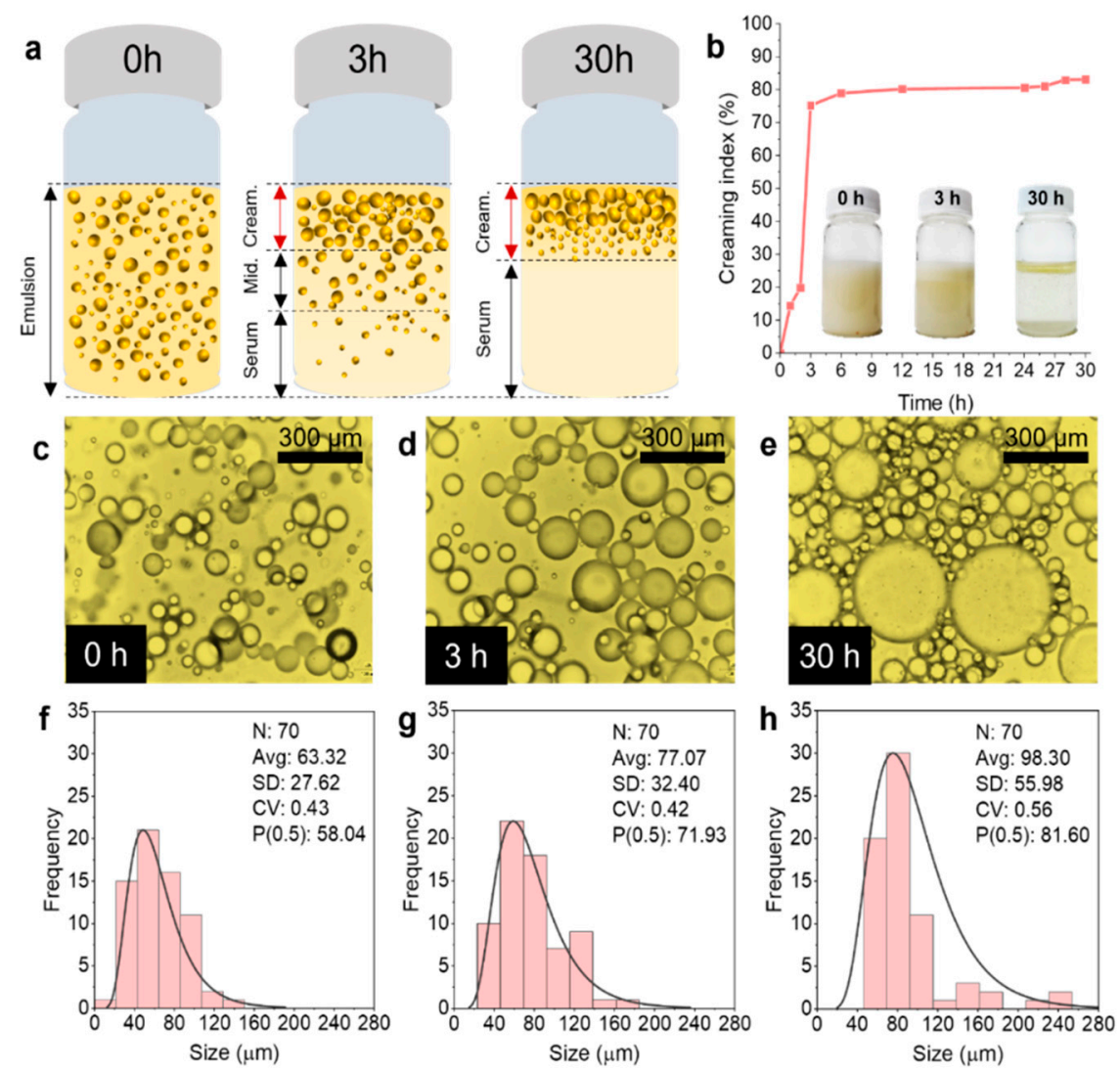

Figure 4. (a) Representation of the creaming evolution over time; (b) Results of creaming index measurements over time; (c-e) Fluorescence microscopy images showing the droplet size evolution over time $(0 \mathrm{~h}, 3 \mathrm{~h}$, and $30 \mathrm{~h}$, respectively); and (f-h) frequency histograms of the droplet diameter fitted to a log-normal distribution at $0 \mathrm{~h}, 3 \mathrm{~h}$, and $30 \mathrm{~h}$.

\subsection{Thermal Stability of Capsule and Their Components}

Moreover, cooking and frying activities involve the oxidation of oils with the consequent loss of unsaturation through bond breaking, additions, substitution, and other well-documented reactions [24]; thus, a significant degradation of the oil is expected after the heating process. Despite this, the FTIR spectra recorded for both VCO and WCO were very similar (see Figure 5a). The disappearance of the -OH stretching characteristic band, at $3350 \mathrm{~cm}^{-1}$, in the WCO could be related to the absence of mono and diglycerides. Meanwhile, the band found at $725 \mathrm{~cm}^{-1}$ is typical of $-\mathrm{CH}_{2}$ rocking, while those at $1100 \mathrm{~cm}^{-1}$ and $1250 \mathrm{~cm}^{-1}$ correspond to the $\mathrm{C}-\mathrm{O}$ stretching vibrations, commonly found in ethers [25]. The vibration of $\mathrm{C}-\mathrm{H}$ bond in methyl groups is confirmed by the absorption bands at $1370 \mathrm{~cm}^{-1}$ and $1450 \mathrm{~cm}^{-1}$, respectively. The strong signal at $1740 \mathrm{~cm}^{-1}$ is typical 
of carbonyl groups $(\mathrm{C}=\mathrm{O})$ in saturated aliphatic ethers, while the bands between 2850 and $3015 \mathrm{~cm}^{-1}$, correspond to symmetrical and nonsymmetrical C-H stretching in methyl $\left(-\mathrm{CH}_{3}\right)$ and methylene $\left(-\mathrm{CH}_{3}\right)$ groups. The similarities in intensity, position and nature of functional groups identified by their characteristic absorption bands in both spectra (VCO and $\mathrm{WCO}$ ), suggest that WCO is thermally stable, which supports its use as encapsulated rejuvenating agent in asphalt materials usually manufactured at a temperature of $160^{\circ} \mathrm{C}$.
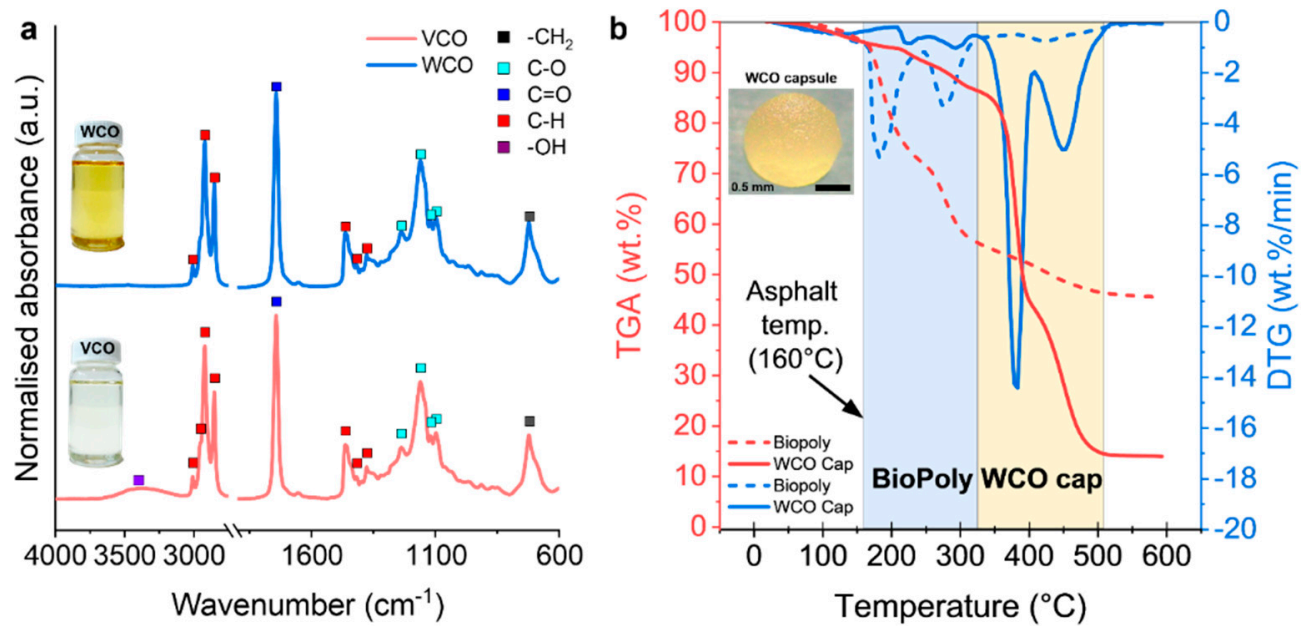

Figure 5. Results of chemical and thermal characterisation of rejuvenating agents (WCO versus VCO), WCO capsule and sodium-alginate biopolymer: (a) Normalised infrared spectra of waste and virgin cooking oil; and (b) TGA results of biopolymer (BioPoly) and WCO capsules (WCO Cap).

Additionally, the thermal stability of the biopolymer (BioPoly) used for the preparation of the WCO capsules was confirmed by the TGA curve in Figure 5b. Indeed, decomposition at $160{ }^{\circ} \mathrm{C}$-temperature of asphalt mixture preparation-, was nearly $5 \%$ for the polymer and remained unchanged when the WCO was encapsulated within the capsules.

Two major DTG peaks corresponding to $12 \%$ and $32 \%$ wt. loss were identified for the BioPoly and, remained similar (with lower intensity) in the WCO Cap. The first peak at $183{ }^{\circ} \mathrm{C}$ is associated with structural dehydration reactions in the alginate, while the second one, at $278{ }^{\circ} \mathrm{C}$, corresponds to the degradation of $\mathrm{CaCO}_{3}$. The weight loss below $300{ }^{\circ} \mathrm{C}$ is caused by the loss of hydroxyl groups in the alginate and above this temperature decarboxylation reactions take place forming $\mathrm{CO}_{2}$ as main product [26].

The relative position of the TGA curve for the WCO capsule indicates a higher thermal stability caused by the presence of the encapsulated WCO. In fact, the first decomposition phase ends at $320{ }^{\circ} \mathrm{C}$ and is associated with the capsule. Above this temperature, the oil decomposes in a two-stage process: the first stage $\left(383^{\circ} \mathrm{C}\right)$ corresponds to scissoring and breakage of $\mathrm{C}-\mathrm{H}$ and $\mathrm{C}-\mathrm{O}$ bonds and, the second (ending at $500{ }^{\circ} \mathrm{C}$ ) corresponds to cross-linking and carbonisation.

Results of TGA are in line with that found in the FTIR and suggest that encapsulation leads to a thermally stable material. Thus, when capsules are incorporated into a hot asphalt mixture, no significative thermal reaction between alginate matrix and asphalt should be expected, maintaining the integrity of the capsule. In fact, Norambuena-Contreras el al. [16] proved that the alginate-based capsules present good thermal and mechanical stability, surviving the mixing and compaction processes showing a strong adhesion to asphalt mastic by effect of a good interlocking with aggregates. They also concluded that capsule content up to $0.5 \%$ wt. of total weight of mixture is adequate to not affect the rheological properties of asphalt. With all these results in hand, capsules could be effectively used for asphalt self-healing application. 


\subsection{Healing Ability of the Encapsulated Rejuvenator}

The healing efficiency of WCO was quantified as a proof of concept in cracked longterm ageing bitumen test samples, see Figure 6a. The crack closure by WCO diffusion (oil amount $2 \mathrm{mg}$ equivalent to the release of the $100 \%$ of WCO from one representative capsule) over time was recorded taking microscopy images during $85 \mathrm{~min}$. As example, Figure $6 \mathrm{~b}-\mathrm{d}$ show fluorescence microscopy images at $0 \mathrm{~min}, 40 \mathrm{~min}$, and $80 \mathrm{~min}$, respectively. Healing efficiency measured in percentage, was quantified as the relationship between the average partial crack-width at a specific time and the average initial crack-width, both measured in $\mu \mathrm{m}$. Fluorescence microscopy shows that WCO can be diffused in the long-term aged bitumen samples reducing their viscosity and contributing to the self-healing of the artificial microcracks. The quantification of the healing effect is presented in Figure 6e, showing that the diffusion of the WCO into the cracked zone reached a maximum healing efficiency of $70 \%$ at $85 \mathrm{~min}$, reducing the initial microcrack width to $60 \mu \mathrm{m}$.
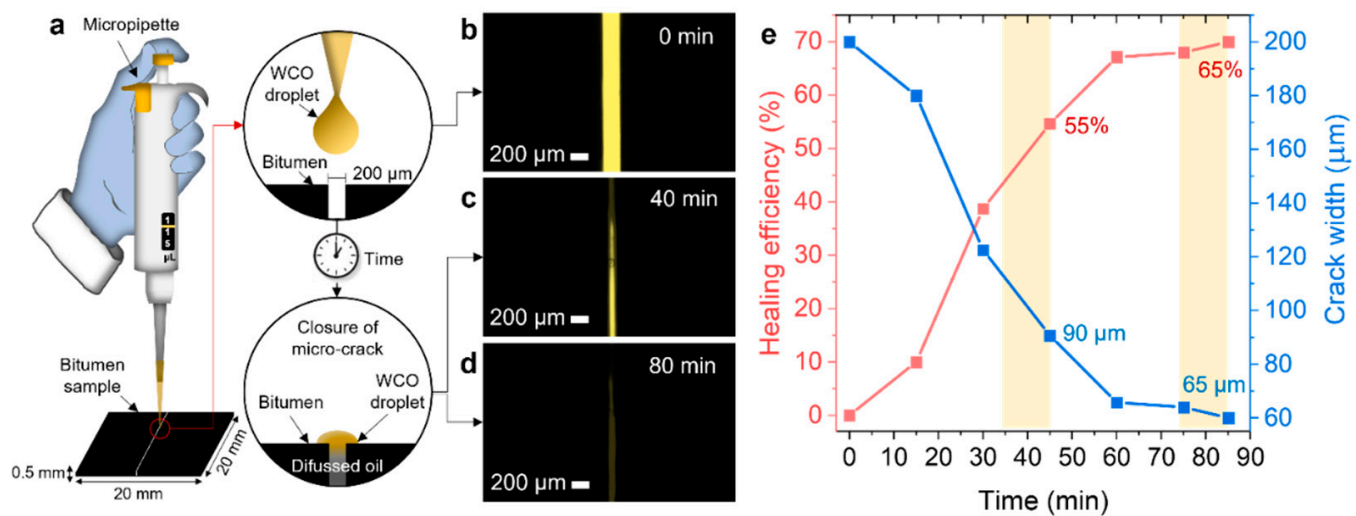

Figure 6. (a) Experimental set-up to evaluate the crack-healing of WCO on a long-term aged bitumen sample; (b-d) Fluorescence microscopy images showing the microcrack closure over time using WCO as healing agent; (e) Results of healing efficiency and crack width measured on the long-term aged bitumen sample.

\section{Conclusions}

This paper evaluated alginate-based polynuclear capsules containing Waste Cooking Oil (WCO) as a promising encapsulated rejuvenator for microcrack self-healing in long-term aged bitumen. Based on the results, the following conclusions have been obtained:

- The encapsulation process by simple extrusion-dripping yielded alginate-based WCO capsules with an adequate encapsulation efficiency and multicavity morphology for asphalt self-healing applications.

- WCO polynuclear capsules and their components presented a good thermal stability and physical-chemical properties. Creaming results showed that encapsulation of the $\mathrm{O} / \mathrm{W}$ emulsion should be addressed during the first $2 \mathrm{~h}$.

- TGA and FTIR tests suggested that the encapsulation process leads to a thermally stable material with potential to be mixed with hot asphalt mixtures for asphalt healing purposes.

- Mechanical characterisation proved that alginate-based WCO capsules can break and partially release the encapsulated WCO oil through an external force trigger effect.

- It was proven through transient oil-bitumen diffusion tests that the encapsulated rejuvenating agent WCO can be diffused in long-term aged bitumen test samples, reducing their viscosity, and hence, healing microcracks present in the asphalt matrix.

Future work of this research will include a comprehensive study to understand the effect of rejuvenating oil type (including Virgin Cooking Oil, Waste Cooking Oil, and Virgin Engine Oil) on the synthesis and properties of alginate-based polynuclear capsules 
for asphalt self-healing. An evaluation of the chemical changes associated with their incorporation into aged bitumen samples (SARA fractions analysis) must be considered.

Author Contributions: Conceptualisation, J.N.-C.; methodology, J.N-C., J.L.C. and I.G.-T.; software, J.N.-C.; validation, J.N.-C. and I.G.-T.; formal analysis, J.N.-C., J.L.C. and L.E.A.-P.; investigation, J.N.-C., J.L.C. and I.G.-T.; resources, J.N.-C. and L.E.A.-P.; data curation, J.N.-C., J.L.C. and I.G.-T.; writing—original draft preparation, J.N.-C. and J.L.C.; writing—review and editing, J.N.-C., J.L.C., L.E.A.-P. and I.G.-T.; visualisation, J.N.-C. and J.L.C.; supervision, J.N.-C.; project administration, J.N.-C.; funding acquisition, J.N.-C. All authors have read and agreed to the published version of the manuscript.

Funding: This research was funded by the National Research and Development Agency (ANID) through the Research Projects FONDECYT 1190027, FONDEQUIP EQMI170077 and CONICYT PIA/Apoyo CCTE 170007.

Data Availability Statement: Not applicable.

Acknowledgments: Second author wishes to thank the financial support given by the University of Bío-Bío for his internal PhD scholarship granted. The authors extend their gratitude to the former student Felipe Muñoz from LabMAT and Rodrigo Briones from CIPA-CONICYT Regional, for their technical support with some laboratory tests.

Conflicts of Interest: The authors declare no conflict of interest.

\section{References}

1. Gonzalez-Torre, I.; Norambuena-Contreras, J. Recent advances on self-healing of bituminous materials by the action of encapsulated rejuvenators. Constr. Build. Mater. 2020, 258, 119568. [CrossRef]

2. Airey, G.D. State of the art report on ageing test methods for bituminous pavement materials. Int. J. Pavement Eng. 2003, 4, 165-176. [CrossRef]

3. Karlsson, R.; Isacsson, U. Investigations on bitumen rejuvenator diffusion and structural stability (with discussion). J. Assoc. Asphalt. Pav. 2003, 72, 463-501.

4. Garcia, A.; Jelfs, J.; Austin, C.J. Internal asphalt mixture rejuvenation using capsules. Constr. Build. Mater. 2015, 101, 309-316. [CrossRef]

5. Su, J.F; Schlangen, E. Synthesis and physicochemical properties of high compact microcapsules containing rejuvenator applied in asphalt. Chem. Eng. J. 2012, 198-199, 289-300. [CrossRef]

6. Su, J.F.; Qiu, J.; Schlangen, E.; Wang, Y.Y. Investigation the possibility of a new approach of using microcapsules containing waste cooking oil: In situ rejuvenation for aged bitumen. Constr. Build. Mater. 2015, 74, 83-92. [CrossRef]

7. Yamaç, Ö.E.; Yilmaz, M.; Yalçın, E.; Kök, B.V.; Norambuena-Contreras, J.; Garcia, A. Self-healing of asphalt mastic using capsules containing waste oils. Constr. Build. Mater. 2021, 270, 121417. [CrossRef]

8. Norambuena-Contreras, J.; Yalcin, E.; Garcia, A.; Al-Mansoori, T.; Yilmaz, M.; Hudson-Griffiths, R. Effect of mixing and ageing on the mechanical and self-healing properties of asphalt mixtures containing polymeric capsules. Constr. Build. Mater. 2018, 175, 254-266. [CrossRef]

9. Norambuena-Contreras, J.; Arteaga-Perez, L.E.; Guadarrama-Lezama, A.Y.; Briones, R.; Vivanco, J.F.; Gonzalez-Torre, I. Microencapsulated bio-based rejuvenators for the self-healing of bituminous materials. Mater 2020, 13, 1446. [CrossRef]

10. Norambuena-Contreras, J.; Arteaga-Pérez, L.E.; Concha, J.L.; Gonzalez-Torre, I. Pyrolytic oil from waste tyres as a promising encapsulated rejuvenator for the extrinsic self-healing of bituminous materials. Road Mater. Pavement Des. 2021, 22, S117-S133. [CrossRef]

11. Xu, S.; Tabaković, A.; Liu, X.; Schlangen, E. Calcium alginate capsules encapsulating rejuvenator as healing system for asphalt mastic. Constr. Build. Mater. 2018, 169, 379-387. [CrossRef]

12. Puscaselu, R.G.; Lobiuc, A.; Dimian, M.; Covasa, M. Alginate: From food industry to biomedical applications and management of metabolic disorders. Polymers 2020, 12, 2417. [CrossRef] [PubMed]

13. Martins, E.; Poncelet, D.; Rodrigues, R.C.; Renard, D. Oil encapsulation techniques using alginate as encapsulating agent: Applications and drawbacks. J. Microencapsul. 2017, 34, 754-771. [CrossRef] [PubMed]

14. Eqbal, M.D.; Gundabala, V. Controlled fabrication of multi-core alginate microcapsules. J. Colloid Interface Sci. 2017, 507, $27-34$. [CrossRef] [PubMed]

15. Norambuena-Contreras, J.; Yalcin, E.; Hudson-Griffiths, R.; García, A. Mechanical and Self-Healing Properties of Stone Mastic Asphalt Containing Encapsulated Rejuvenators. J. Mater. Civ. Eng. 2019, 31, 04019052. [CrossRef]

16. Norambuena-Contreras, J.; Liu, Q.; Zhang, L.; Wu, S.; Yalcin, E.; Garcia, A. Influence of encapsulated sunflower oil on the mechanical and self-healing properties of dense-graded asphalt mixtures. Mater. Struct. Constr. 2019, 52, 1-13. [CrossRef]

17. Ruiz-Riancho, N.; Garcia, A.; Grossegger, D.; Saadoon, T.; Hudson-Griffiths, R. Properties of Ca-alginate capsules to maximise asphalt self-healing properties. Constr. Build. Mater. 2021, 284, 122728. [CrossRef] 
18. ASTM D6521-19; Standard Practice for Accelerated Aging of Asphalt Binder Using a Pressurised Aging Vessel (PAV). ASTM International: West Conshohocken, PA, USA, 2019.

19. Guadarrama-Lezama, A.Y.; Dorantes-Alvarez, L.; Jaramillo-Flores, M.E.; Pérez-Alonso, C.; Niranjan, K.; Gutiérrez-López, G.F.; Alamilla-Beltrán, L. Preparation and characterization of non-aqueous extracts from chilli (Capsicum annuum L.) and their microencapsulates obtained by spray-drying. J. Food Eng. 2012, 112, 29-37. [CrossRef]

20. ASTM D792-13; Standard Test Methods for Density and Specific Gravity (Relative Density) of Plastics by Displacement. ASTM International: West Conshohocken, PA, USA, 2013.

21. ASTM D695-02a; Standard Test Method for Compressive Properties of Rigid Plastics. ASTM International: West Conshohocken, PA, USA, 2002.

22. McClements, D.J. Critical review of techniques and methodologies for characterisation of emulsion stability. Crit. Rev. Food Sci. Nutr. 2007, 47, 611-649. [CrossRef]

23. Concha, J.L.; Arteaga-Pérez, L.; Gonzalez-Torre, I.; Norambuena-Contreras, J. Biocapsules Containing Low-Cost Rejuvenators for Asphalt Self-Healing. RILEM Tech. Lett. 2021, 6, 1-7. [CrossRef]

24. Rayhan, B.A.; Kamal, H. Waste cooking oil as an asphalt rejuvenator: A state-of-the-art review. Constr. Build. Mater. 2020, 230, 116985.

25. Atabani, A.E.; Shobana, S.; Mohammed, M.N.; Uğuz, G.; Kumar, G.; Arvindnarayan, S.; Aslam, M.; Al-Muhtaseb, A.H. Integrated valorization of waste cooking oil and spent coffee grounds for biodiesel production: Blending with higher alcohols, FT-IR, TGA, DSC and NMR characterizations. Fuel 2019, 244, 419-430. [CrossRef]

26. Zhao, W.; Qi, Y.; Wang, Y.; Xue, Y.; Xu, P.; Li, Z.; Li, Q. Morphology and Thermal Properties of Calcium Alginate/Reduced Graphene Oxide Composites. Polymers 2018, 10, 990. [CrossRef] [PubMed] 